\title{
Induction of PD-LI expression by epidermal growth factor receptor-mediated signaling in esophageal squamous cell carcinoma
}

This article was published in the following Dove Press journal:

OncoTargets and Therapy

13 February 2017

Number of times this article has been viewed

\author{
Wencheng Zhang,' Qingsong \\ Pang,' Cihui Yan, ${ }^{2}$ Qifeng \\ Wang, ${ }^{3}$ Jingsong Yang, ${ }^{3}$ \\ Shufei Yu, ${ }^{3}$ Xiao Liu, ${ }^{3}$ \\ Zhiyong Yuan,' Ping Wang,' \\ Zefen Xiao ${ }^{3}$ \\ 'Department of Radiation Oncology, \\ 2Department of Immunology, Tianjin \\ Medical University Cancer Institute \\ and Hospital, National Clinical \\ Research Center of Cancer, Key \\ Laboratory of Cancer Prevention \\ and Therapy, Tianjin, People's \\ Republic of China; ${ }^{3}$ Department \\ of Radiation Oncology, Cancer \\ Institute and Hospital, Chinese \\ Academy of Medical Sciences and \\ Peking Union Medical College, \\ Beijing, People's Republic of China
}

Correspondence: Zefen Xiao Department of Radiation Oncology, National Cancer Center/Cancer Hospital, Chinese Academy of Medical Sciences and Peking Union Medical College, Pan Jia Yuan Nanli 17\#, Chaoyang District, Beijing, I0002I, People's Republic of China

Tel +86 I0 87788503

$\mathrm{Fax}+861067706153$

Email xiaozefen2013@163.com

Ping Wang

Department of Radiation Oncology, Tianjin Medical University Cancer Institute and Hospital, National Clinical Research Center of Cancer, Key Laboratory of Cancer Prevention and Therapy, Huan-Hu-Xi Road, Ti-Yuan-Bei, Hexi District, Tianjin, 300060, People's Republic of China Tel +86 22 235। 9953

Fax +86 222334 I 405

Email wangping@tjmuch.com
Purpose: The purpose of this study was to investigate the potential effect of activation of epidermal growth factor receptor (EGFR) signaling pathway on the expression of programmed death-ligand 1 (PD-L1) in esophageal squamous cell carcinoma (ESCC) cells with EGFR overexpression.

Methods: Flow cytometry and Western blot methods were used to assess PD-L1 expression on ESCC cells when EGFR signaling pathway was activated by epidermal growth factor (EGF) with or without EGFR-specific inhibitor AG-1478, and then EGFR signaling array was applied to analyze the potential signaling pathways involved.

Results: This study found that PD-L1 expression increased significantly in an EGFR-dependent manner by the activation of EGFR signaling and decreased sharply when EGFR signaling was blocked. The upregulated expression of PD-L1 was not associated with EGFR-STAT3 signaling pathway, but may be affected by EGFR-PI3K-AKT, EGFR-Ras-Raf-Erk, and EGR-PLC- $\gamma$ signaling pathways.

Conclusion: The expression of PD-L1 can be regulated by EGFR signaling activation in ESCC, which indicates an important role for EGFR-mediated immune escape and potential molecular pathways for EGFR-targeted therapy and immunotherapy.

Keywords: epidermal growth factor receptor, programmed death-ligand 1, esophageal squamous cell carcinoma, immune checkpoint

\section{Introduction}

Esophageal cancer is the eighth most common cancer and the sixth leading cause of cancer-related mortality in the world. ${ }^{1}$ Previous studies found that overexpression of epidermal growth factor receptor (EGFR) occurs in $42.5 \%-85.7 \%$ of esophageal squamous cell carcinoma (ESCC) and is closely associated with high recurrence and shorter survival rate. ${ }^{2-6}$ Activation of EGFR may trigger a series of intracellular signaling pathways, which plays an important role in cell proliferation, apoptosis, angiogenesis, and metastasis..$^{7-9}$ It also involves suppressing immune response through either activating regulatory $\mathrm{T}$ cells or reducing the level of T-cell chemoattractant. ${ }^{10}$ Monoclonal antibodies and tyrosine kinase inhibitors against EGFR have been developed to improve the survival rate of ESCC, while most patients did not benefit from it. ${ }^{11,12}$

Tumor cells can express many immune inhibitory proteins, which contribute to dysfunction and apoptosis of immune cells. ${ }^{13}$ Programmed death-ligand 1 (PD-L1; also called B7-H1 or CD274), which is expressed on many cancer cells, is one of the most important inhibitory molecular which promotes tumor immune escape. ${ }^{14,15}$ PD-L1 binds its receptors PD-1 and B7.1 (CD80), leading to negative regulation of 
T-lymphocyte activation. ${ }^{16}$ Although the association between PD-L1 expression and prediction of prognosis in patients with cancer is controversial, ${ }^{17-20}$ anti-PD-L1 and anti-PD-1 antibodies have shown encouraging preliminary activity and those that have been used in patients exhibit promising safe profiles and outcome. ${ }^{21-25}$ Further understanding of the regulatory mechanism of $\mathrm{PD}-\mathrm{L} 1$ expression is important for improving prognosis and evaluating potential targets in cancer therapy.

It was reported that mutant EGFR signaling pathway activation induced PD-L1 expression on bronchial epithelial cells, and EGFR inhibitors could decrease the upregulated PD-L1 expression in non-small-cell lung cancer (NSCLC) cell lines. ${ }^{26}$ It was also reported that there was no significant relations between PD-L1 and EGFR/KRAS expression in lung adenocarcinoma. ${ }^{27}$ In head and neck cancer, PD-L1 expression was induced in an EGFR-dependent manner by JAK2-STAT1 downstream pathway. ${ }^{28}$ In ESCC cells, PD-L1 expression was regulated by interleukin-6-PI3K signaling pathway. ${ }^{29}$ However, the relationship between EGFR overexpression and PD-L1 expression in ESCC cells is less known. This study assessed PD-L1 expression on ESCC cells after EGFR signaling was activated by epidermal growth factor (EGF) stimulation and screened the potential signaling pathways involved. It was found that PD-L1 expression was regulated by EGFR activation efficiently, which may provide new strategies in targeted tumor therapy.

\section{Materials and methods Cell culture}

Esophageal squamous cell lines kyse30, TE7, TE1, Eca109, kyse140, kyse 510, and CaEs-17 were maintained in RPMI1640 (Invitrogen, Carlsbad, CA, USA) supplemented with $2 \mathrm{mmol} / \mathrm{L}$ L-glutamine, 100 units/mL penicillin (Hyclone; GE Healthcare Life Sciences, Logan, UT, USA), $100 \mu \mathrm{g} / \mathrm{mL}$ streptomycin (GE Healthcare Life Sciences), and 10\% fetal calf serum (ThermoFisher Scientific, Grand Island, NY, USA). Cells were incubated at $37^{\circ} \mathrm{C}$ in a humidified atmosphere containing $5 \% \mathrm{CO}_{2}$ and used in the experiments when in logarithmic growth phase.

\section{Cell treatment}

After the cells were starved overnight, EGF (Perprotech, Rocky Hill, NY, USA) was added to the culture media at the final concentration of $20 \mathrm{ng} / \mathrm{mL} \cdot{ }^{30,31}$ EGFR tyrosine kinase inhibitor AG1478 (Selleck, Houston, TX, USA) was dissolved in dimethyl sulfoxide and added $30 \mathrm{~min}$ earlier at a final concentration of 1,5 , or $10 \mu \mathrm{M}$ before EGF treatment.

\section{Western blot}

Cells were lysed and proteins were extracted using mammalian protein extraction agent (ThermoFisher Scientific Pierce, Waltham, MA, USA) plus Halt protease inhibitor cocktail (ThermoFisher Scientific Pierce). Protein concentrations were determined using bicinchoninic acid (BCA) protein assay kit (ThermoFisher Scientific Pierce). Aliquots of protein lysates were separated on sodium dodecyl sulfate-polyacrylamide gels and transferred onto a nitrocellulose membrane, which was blocked with $5 \%$ blotting grade milk (Bio-Rad, Hercules, CA, USA) in PBST ( $0.1 \%$ Tween 20 in phosphate-buffered saline [PBS]). The membrane was then hybridized with the indicated primary antibodies specific to human EGFR, phospho-EGFR (Tyr1068), STAT3, and phospho-STAT3 (Tyr705), then with the corresponding secondary antibodies conjugated with horseradish peroxidase, and detected using a chemiluminescence assay (EMD Millipore, Temecula, CA, USA). Membranes were exposed to X-ray film (Kodak China Investment, Shanghai, People's Republic of China) to visualize the bands. $\beta$-Actin was used as loading control. All primary and secondary antibodies used in the Western blotting were purchased from Cell Signaling Technology (Danvers, MA, USA).

\section{Flow cytometry}

The cells were collected and washed twice in cold flow cytometry staining buffer ( $\mathrm{pH} 7.4 \mathrm{PBS}$ containing $0.2 \%$ [w/v] bovine serum albumin), then resuspended with cold staining buffer to a final concentration of $10^{7} / \mathrm{mL}$. Cell suspension was aliquoted into $100 \mu \mathrm{L}$ to each tube and $5 \mu \mathrm{L}$ of directly conjugated primary antibodies was added. After incubating for $30 \mathrm{~min}$ on ice protected from light, cells were washed twice with staining buffer to remove unbound antibodies and then analyzed by flow cytometry immediately. For intracellular staining, the fixation and permeabilization (catalog no 554714, BD Biosciences, San Jose, CA, USA) steps were performed after the surface staining. And then intracellular markers were stained. The primary antibodies (PE-PD-L1, catalog no 558091; and PerCP-Cy5.5-EGFR catalog no 352914) were both purchased from BD Biosciences.

\section{PathScan ${ }^{\circledR}$ EGFR signaling array analysis}

EGFR downstream signaling pathways were analyzed using PathScan ${ }^{\circledR}$ EGFR signaling array kit (Cell Signaling Technology, catalog no 12785) according to the manufacturer's instructions. First, cell lysates were prepared. Cells cultured in $10 \mathrm{~cm}$ plate were washed once with ice-cold PBS and $0.5 \mathrm{~mL}$ of ice-cold cell lysis buffer was added to each plate on ice for $2 \mathrm{~min}$. Tilt the plate, scrape the cells, and collect the lysate into a clean microcentrifuge tube. Microcentrifuge the 
lysate at maximum speed for $3 \mathrm{~min}$ at $4^{\circ} \mathrm{C}$. The supernatant was aliquoted and stored at $-80^{\circ} \mathrm{C}$. The second step is the assay procedure. The multi-well gasket was affixed to the glass slide, and $100 \mu \mathrm{L}$ of array blocking buffer was added to each well and incubated for $15 \mathrm{~min}$ at room temperature on an orbital shaker. The array blocking buffer was decanted. Then, $75 \mu \mathrm{L}$ of diluted lysate was added to both subarray A and subarray B. The array was covered with sealing tape and incubated for $2 \mathrm{~h}$ at room temperature on an orbital shaker and the well contents were decanted. Later, $100 \mu \mathrm{L}$ of array wash buffer was added and incubated for $5 \mathrm{~min}$ at room temperature on an orbital shaker. This process is repeated for three more times. Then, $75 \mu \mathrm{L}$ of detection antibody cocktails A was added, covered with a sealing tape, and incubated for $1 \mathrm{~h}$ at room temperature on an orbital shaker. The slide was washed four times for $5 \mathrm{~min}$ with $100 \mu \mathrm{L}$ of array wash buffer. Then, $75 \mu \mathrm{L}$ of DyLight $680^{\mathrm{TM}}$-linked Streptavidin was added and incubated for $30 \mathrm{~min}$ at room temperature on an orbital shaker. The slide was washed four times for $5 \mathrm{~min}$ with $100 \mu \mathrm{L}$ of array wash buffer. Later, the slide was peeled and the gasket was kept apart. The slide was then washed once for $10 \mathrm{~s}$ with $10 \mathrm{~mL}$ of deionized water and allowed to dry completely. The image of the slide was captured by using Odyssey ${ }^{\circledR}$ (LI-COR Biosciences, Lincoln, NE, USA) imaging system excited at $680 \mathrm{~nm}$ and detected at
$700 \mathrm{~nm}$. Spot intensities were quantified by using the Image Studio v2.0 array analysis software (LI-COR Biosciences). The heatmap was drawn using Heml 1.0 software (CUCKOO Workgroup, Hubei, People's Republic of China).

\section{Statistical methodology}

Data are represented as mean \pm standard deviation. Differences between groups were examined for significant differences by analysis of variance least significant difference procedure. Values of $P<0.05$ were considered to be statistically significant. All the tests were performed in SPSS Statistics 22.0 software (IBM Corporation, Armonk, NY, USA).

\section{Results \\ PD-LI expression on ESCC cells in complete culture media}

Firstly, the expression of PD-L1 on ESCC cell lines with different levels of EGFR overexpression was evaluated in the complete culture media. Seven ESCC cell lines were used in these experiments. The Western blot result showed that kyse30 cells had the highest expression of EGFR, TE7, TE1, and Eca109; kyse140 cells had a moderate expression; and kyse 510 and CaEs-17 cells had the lowest expression (Figure 1A). The EGFR expression on cell surface was tested by flow cytometry (Figure 1B). As part of EGFR was located in cytoplasm during
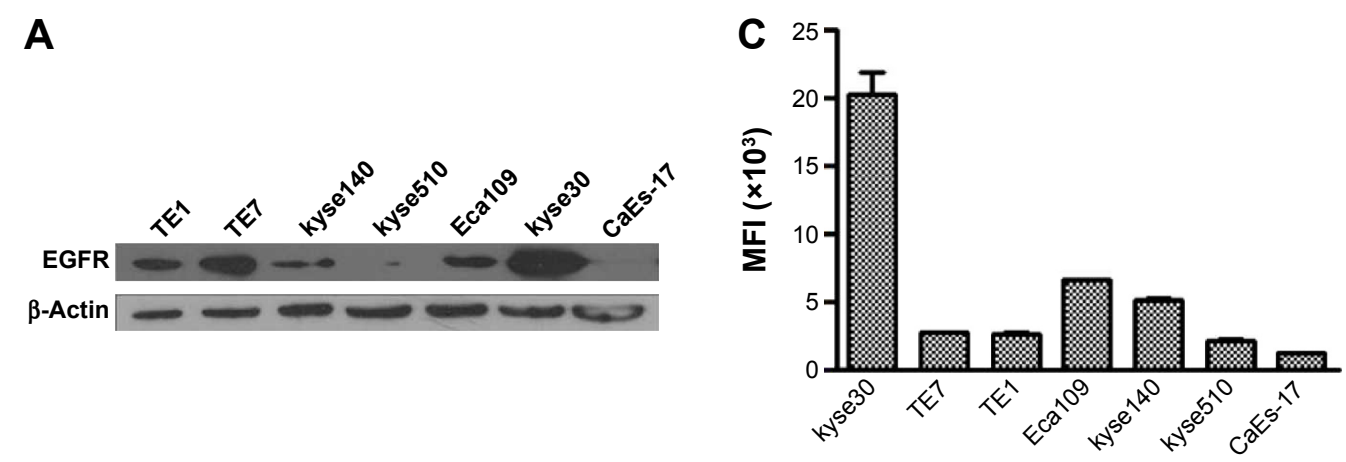

B

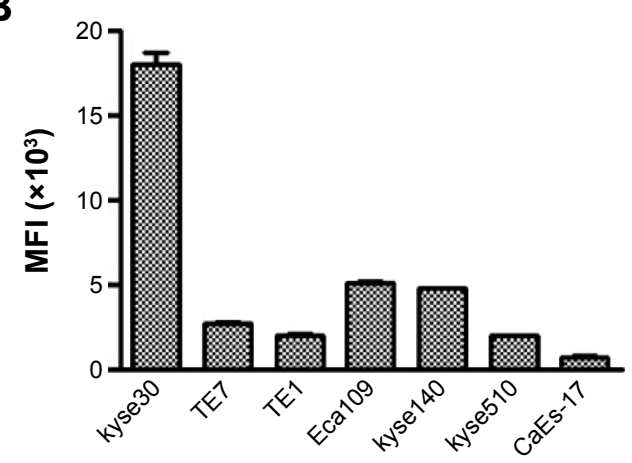

D

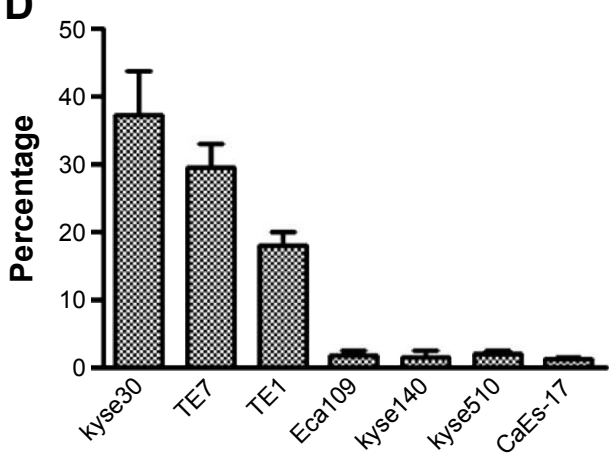

Figure I EGFR and PD-LI expressions of ESCC cells in complete culture media.

Notes: EGFR (A-C) and PD-LI (D) expressions were tested by Western blot (A) and flow cytometry (B-D). (B and C) Cell surface and total EGFR expression.

Abbreviations: EGFR, epidermal growth factor receptor; PD-LI, programmed death-ligand I; ESCC, esophageal squamous cell carcinoma; MFI, median fluorescence intensity. 
rest condition, the total EGFR expression was also evaluated by staining EGFR both on surface and in cytoplasm (Figure 1C), which showed similar levels as that on surface. These results confirmed the different levels of EGFR expression in ESCC cell lines. When cultured in complete culture media, the cells had different levels of PD-L1 expression in a pattern similar to the level of EGFR expression (Figure 1D).

\section{PD-LI expression induced by EGF}

To exclude the potential effect of cytokines in the serum of complete culture media, the cells were starved overnight and then PD-L1 expressions on cells with or without exogenous EGF added were compared. After 24 h of EGF treatment, the expression of PD-L1 elevated highest in kyse30 cells and moderate in TE7, TE1, Eca109, and kyse140 cells $(P<0.05)$, whereas no significant increase was found in kyse 510 and CaEs-17 cells $(P>0.05)$ (Figure $2 \mathrm{~A})$. When kyse 30 and TE- 1 cells were pretreated with EGFR tyrosine kinase inhibitor AG1478, the upregulated percentage of PD-L1 induced by EGF decreased significantly (Figure 2B-D).

\section{PD-LI expression not influenced by EGFR-STAT3 signaling pathway}

As shown in Figure 3, EGF increased the level of phosphorylated EGFR significantly in ESCC cells whether they had high or low EGFR expression. The upregulated EGFR phosphorylation could be inhibited efficiently by EGFR tyrosine kinase inhibitor AG1478. The effect of STAT3 signaling due to its potential effect on immune escape was then investigated. Unexpectedly, the same changes of phosphorylation of STAT3 were found as phosphorylation of EGFR occurred only in kyse 30 cells, not in TE1 and CaEs-17 cells.

\section{Potential EGFR signaling pathways involved in the regulation of PD-LI expression}

To further assess the molecular pathways involved in PD-L1 expression in ESCC cells following EGFR activation, the EGFR downstream signaling pathways were examined in wild-type EGFR expression kyse30 and TE1 cells, and EGFR mutant TE7 cells using PathScan ${ }^{\circledR}$ EGFR signaling antibody array kit. This study used 1.5 cutoffs to predict the significant

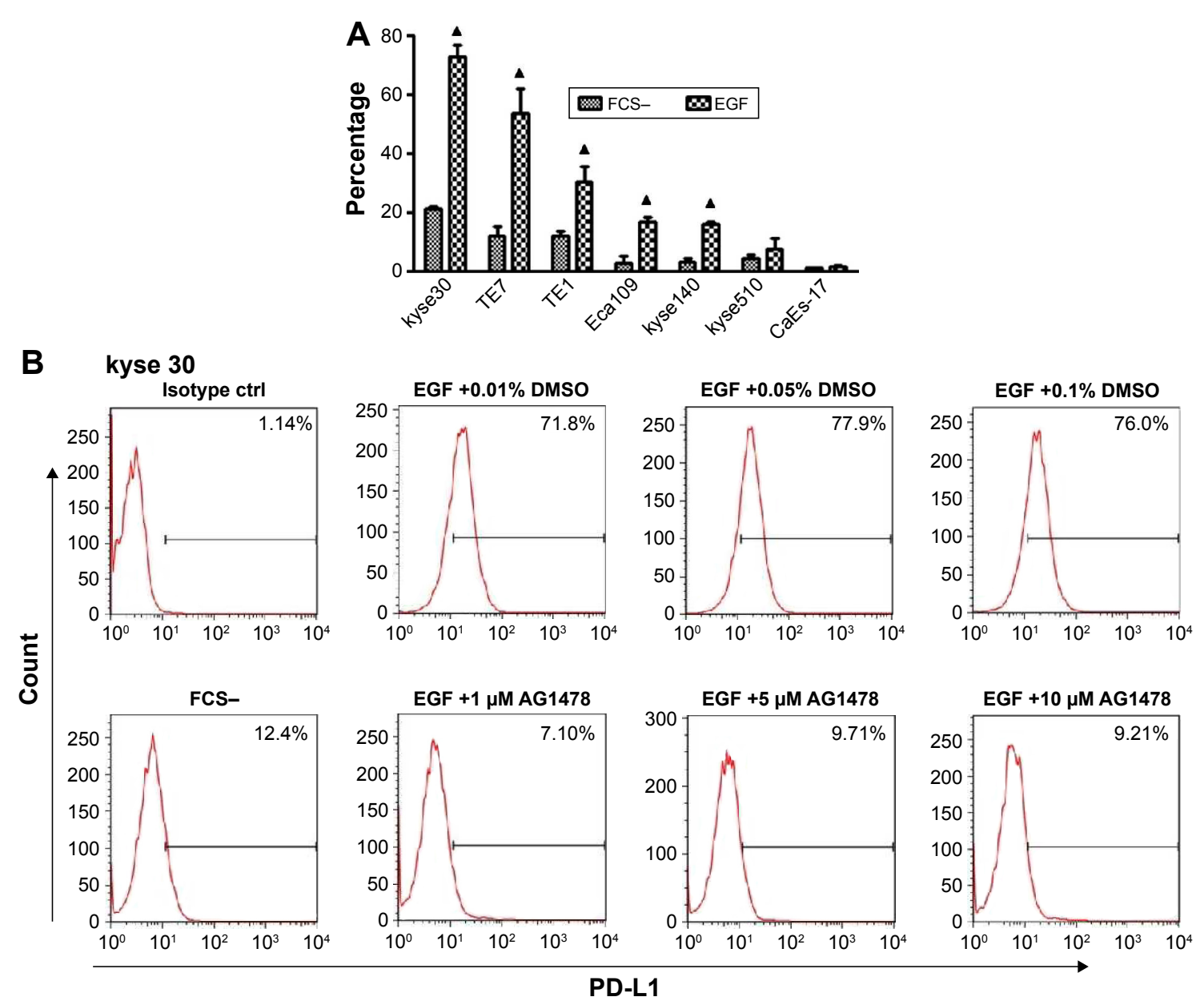

Figure 2 (Continued) 


\section{TE1}


PD-L1

D

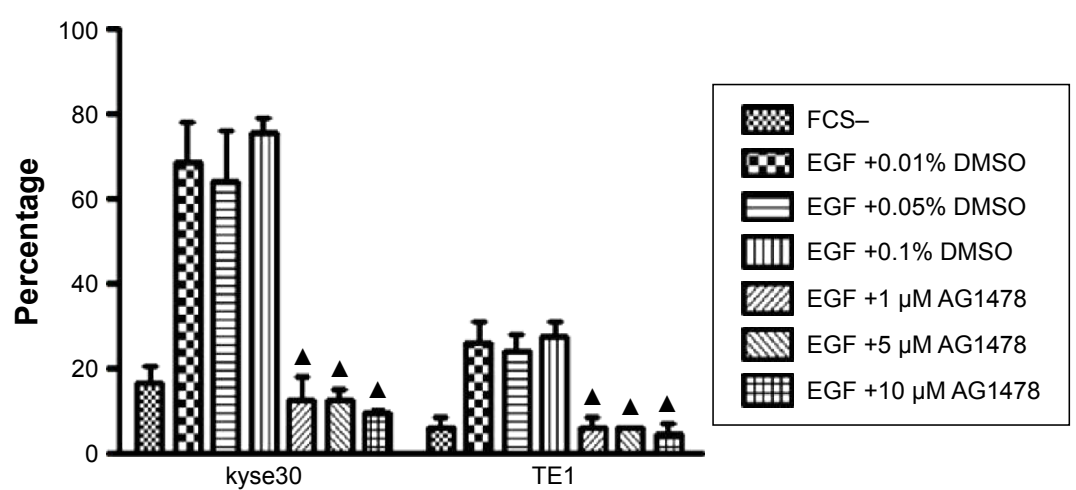

Figure $2 \mathrm{PD}-\mathrm{LI}$ was induced by EGF.

Notes: (A) PD-LI expression after EGF treatment. ESCC cells were starved overnight and treated with EGF (20 ng/mL). After $24 \mathrm{~h}$, PD-LI expression was tested by flow cytometry. (B and C) AGI478 inhibited EGF-induced PD-LI expression. Indicated concentration of AGI478 was added 30 min before EGF treatment. (D) Three repeated experiments for $\mathbf{B}$ and $\mathbf{C} . \wedge P<0.05$ as significant difference.

Abbreviations: PD-LI, programmed death-ligand I; EGF, epidermal growth factor; ESCC, esophageal squamous cell carcinoma; FCS, fetal calf serum; DMSO, dimethyl sulphoxide.

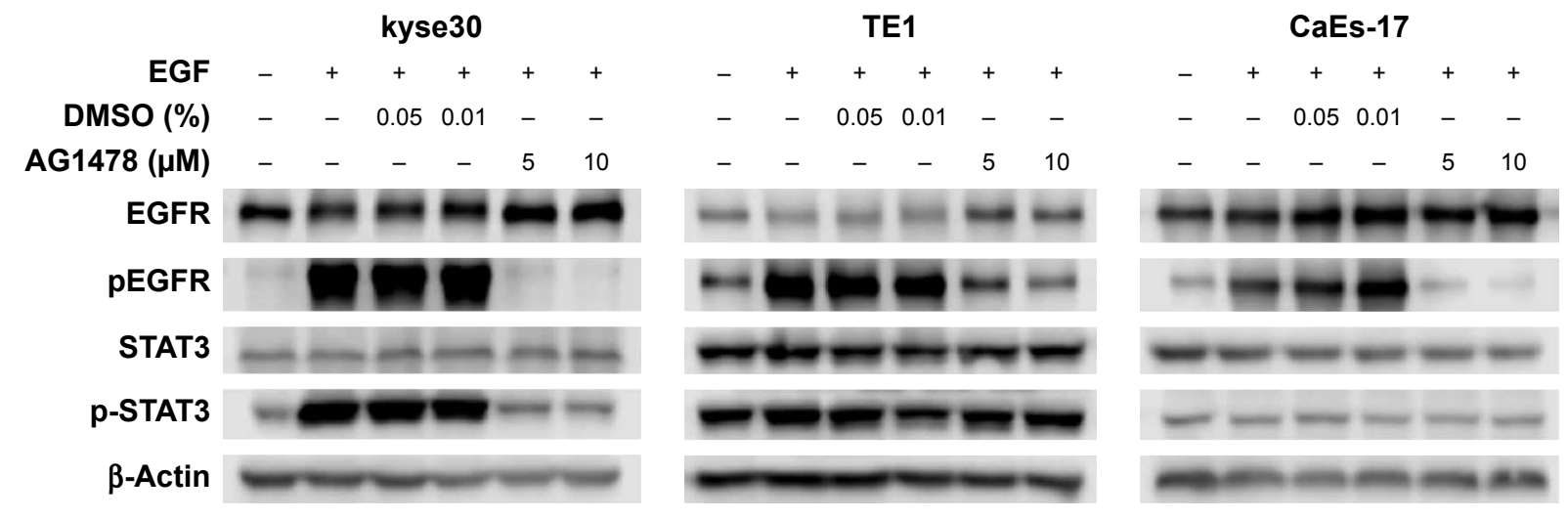

Figure 3 PD-LI was not influenced by EGFR-STAT3 signaling pathway.

Notes: ESCC cells were starved overnight and treated with EGF $(20 \mathrm{ng} / \mathrm{mL})$ for 30 min or pretreated with AG I 478. Total protein was extracted and tested using Western blot. Abbreviations: EGFR, epidermal growth factor receptor; PD-LI, programmed death-ligand I; EGF, epidermal growth factor; ESCC, esophageal squamous cell carcinoma; DMSO, dimethyl sulphoxide; STAT3, signal transducer and activator of transcription 3. 
A

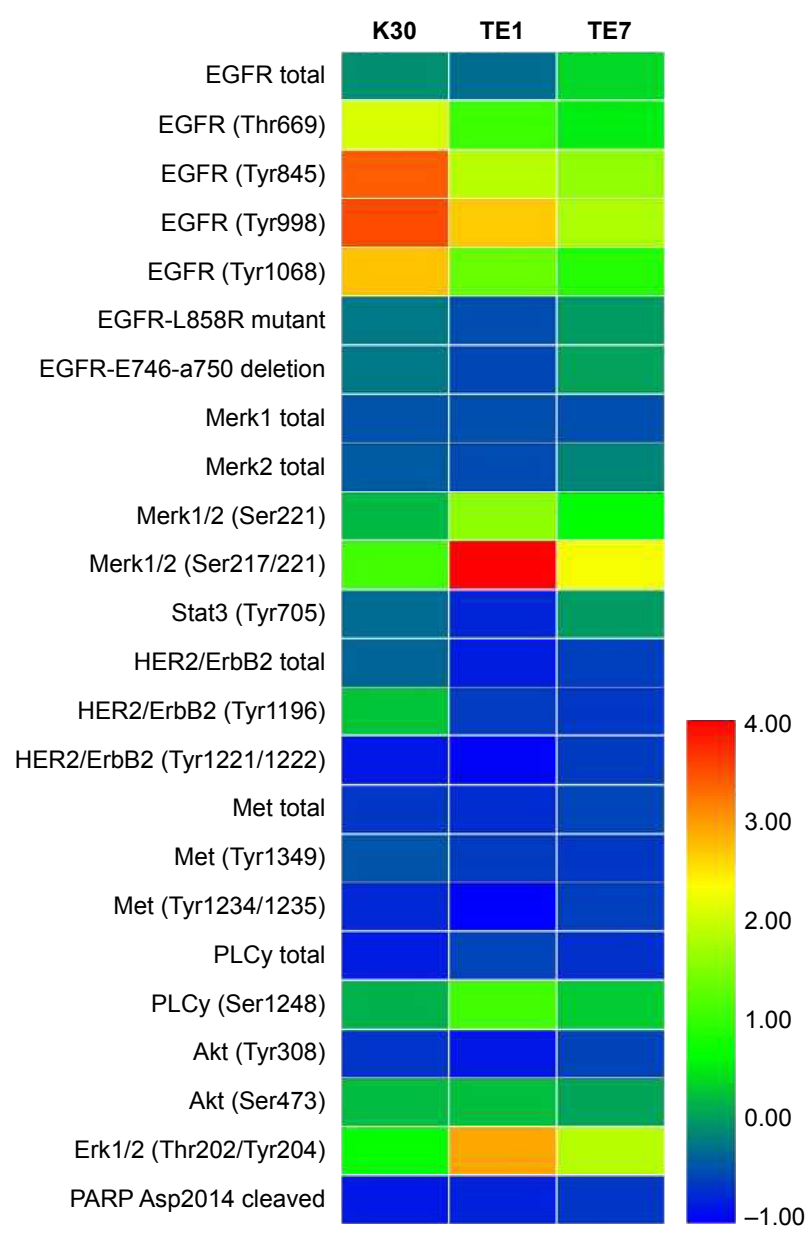

B
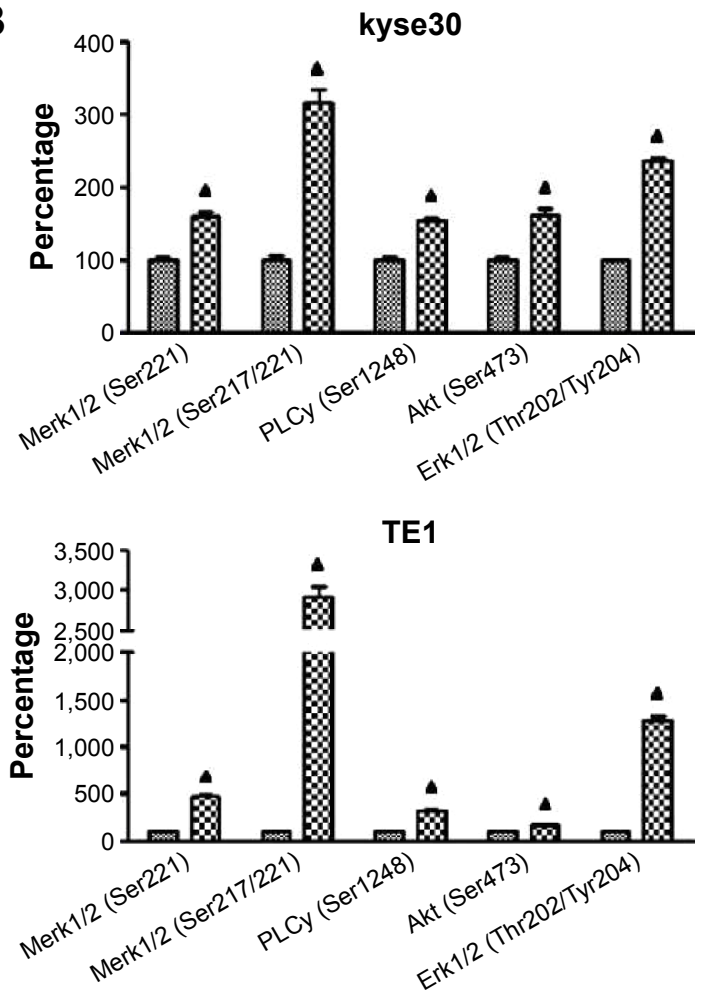

TE7

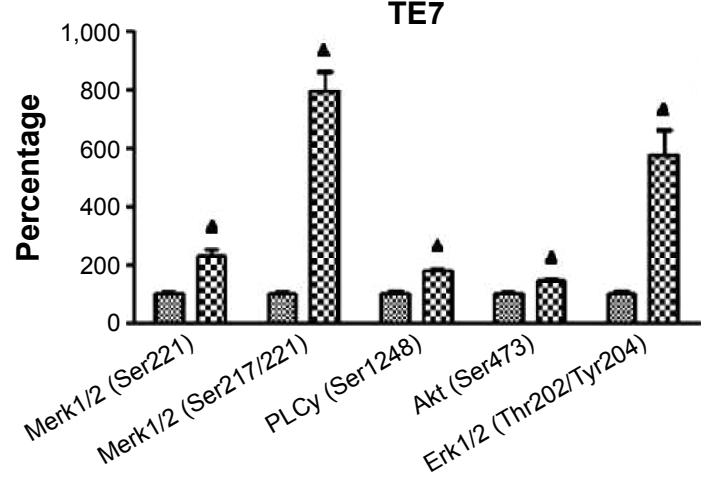

Figure 4 Potential EGFR signaling pathways involved in the regulation of PD-LI expression.

Notes: Starved ESCC cells were treated with EGF $(20 \mathrm{ng} / \mathrm{mL})$ for 30 min and analyzed using PathScan ${ }^{\circledR}$ EGFR signaling antibody array kit. (A) Heatmap illustrator. (B) Increased phosphorylation in ESCC cells. Cutoff $>$ I.5. $\triangle P<0.05$ as significant difference.

Abbreviations: EGFR, epidermal growth factor receptor; PD-LI, programmed death-ligand I; EGF, epidermal growth factor; ESCC, esophageal squamous cell carcinoma; FCS, fetal calf serum.

changes of the tested proteins. As shown in Figure 4, EGF initiated the activation of EGFR signaling pathways as the fluorescent signal of phosphorylated EGFR increased significantly. The levels of phosphorylated Mek1/2, PLC- $\gamma$, Akt, and Erk1/2 were enhanced obviously in EGF-treated cells compared with that of starved cells. Similar results were found in all these three cell lines, which indicated that EGFR-PI3K-AKT, EGFR-Ras-Raf-Erk, and EGR-PLC- $\gamma$ signaling pathways may participate in the regulation of PD-L1 expression.

\section{Discussion}

The relationship between EGFR and PD-L1 has attracted much more attention in recent years. The present study found that PD-L1 was induced by EGFR activation following EGF stimulation in ESCC cells. This upregulated expression was not associated with EGFR-STAT3 signaling pathway but may be involved in EGFR-PI3K-AKT, EGFR-Ras-RafErk, and EGR-PLC- $\gamma$ signaling pathways.

It was found that PD-L1 expression was induced significantly in an EGFR-dependent manner when EGFR signaling 
pathways were activated by EGF in ESCC cells. The cells were starved overnight to exclude the potential effect of cytokines in the serum of complete culture media on the activation of EGFR signaling pathways. EGFR tyrosine kinase inhibitor can inhibit PD-L1 expression induced by EGF even lower than the basic level. This result indicated that PD-L1 expression was regulated by the activation of EGFR signaling pathways. In NSCLC, it was reported that PD-L1-positive status was significantly associated with the presence of EGFR mutation, ${ }^{32}$ could be induced by activation of EGFR mutant that contributed to immune escape, ${ }^{26}$ and had better outcome by EGFR-tyrosine kinase inhibitors. ${ }^{33}$ However, there was a controversial report that showed that there was no significant relationship between PD-L1 expression and EGFR/KRAS expression in lung adenocarcinoma. ${ }^{27}$ As EGFR gene mutation leading to the constitutive activation of EGFR signaling pathways is most common in lung cancer, there may be some difference in PD-L1 expression in ESCC because EGFR overexpression is the main reason for the dysregulation of EGFR signaling pathways in ESCC.

This study found that there was a basic low level of PD-L1 expression in starved cells. While upon EGF stimulation, PD-L1 expression increased sharply in ESCC cells with high and moderate EGFR expression. Two mechanisms are involved in the upregulation of PD-L1 expression in cancer, namely intrinsic and adaptive immune resistance. ${ }^{34}$ Intrinsic resistance refers to constitutive expression of PD-L1 by tumor cells because of change of certain signaling pathways, such as AKT pathway and STAT3. ${ }^{35,36}$ The low level of PD-L1 expression in starved condition probably resulted from low level of activation of EGFR signaling pathways because of autocrine effect or other mechanisms besides EGFR signaling activation. In adaptive resistance, the induction of PD-L1 on tumor cells is response to specific cytokines, such as interferon- $\gamma$ produced by activated $\mathrm{CD}^{+} \mathrm{T}$ cells, $\mathrm{CD} 8^{+}$ $\mathrm{T}$ cells, and natural killer cells. ${ }^{37,38}$ These results suggest that except for interferon- $\gamma$ from activated immune cells, other cytokines, such as EGF, commonly thought as one of the major contributor to tumor development when binding EGFR, and some therapeutic intervention, such as chemotherapy and radiotherapy, are also very important inducers to adaptive PD-L1 expression. This study did not find any significant increase of PD-L1 expression in low EGFR expression cells by EGF stimulation, which indicated that the signal strength from the activation of EGFR signaling was vital to initiate PD-L1 expression; a threshold value was required for this induction.
An increased phosphorylation of STAT3 only in kyse30 cells was found after EGF treatment but not in TE1 cells, although PD-L1 expression was induced in both of these cell lines. STAT3 has been identified to regulate PD-L1 transcription. Histone deacetylase 6 regulated PD-L1 expression by recruiting and activating STAT3 in melanoma. ${ }^{39}$ In head and neck squamous cell carcinoma, the intrinsic oncogenic signaling mostly depends on overexpressed wild-type EGFR stimulation, which is presented as a unique feature of this type of cancer, and JAK-STAT3 oncogenic pathway is best characterized in tumor proliferation and survival. ${ }^{40}$ Different results indicated that the transcriptional factor STAT3 might not be a common mechanism driving PD-L1 expression in ESCC. Similar results have been reported that STAT3 expression was not correlated with PD-L1 expression in high EGFR expression tumor specimens of head and neck cancer, ${ }^{28}$ and STAT3 inhibitor could not reduce PD-L1 expression in EGFR mutant lung cancer cells although it attenuated STAT3 phosphorylation. ${ }^{41}$

EGFR-related signaling pathways are complicated and interlocked with each other. Mutant EGFR upregulated PD-L1 by activating $\mathrm{PI} 3 \mathrm{~K}-\mathrm{AKT}$ and $\mathrm{MEK}-\mathrm{ERK}$ signaling pathways in NSCLC. ${ }^{41}$ It was also reported that control of PD-L1 expression was specific to the PI3K-AKT-mTOR pathway and was not due to the stimulation of the MEK-ERK pathway in NSCLC cells. ${ }^{42}$ Contrastingly, another study reported that EGFR activation by EGF stimulation, exon-19 deletions, and L858R mutation could induce PD-L1 expression through p-ERK1/2-p-c-Jun but not through p-AKT-p-S6 pathway in EGFR-driven NSCLC. ${ }^{43}$ This disagreement may result from different derivation of human and mouse cells. This study found that the levels of phosphorylated Mek1/2, PLC- $\gamma$, Akt, and Erk1/2 increased significantly after EGF stimulus, which might involve EGFR-PI3K-AKT, EGFR-Ras-Raf-MekErk, and EGFR-PLC- $\gamma$ signaling pathways. Activation of PLC- $\gamma$ can activate the downstream signaling factors protein kinase $\mathrm{C}(\mathrm{PKC})$ and $\mathrm{NF}-\kappa \mathrm{B}$. NF- $\kappa \mathrm{B}$ was reported to promote PD-L1 expression in ovarian cancer. ${ }^{44}$ Moreover, both PKC and AKT activation lead to Ras-mediated downstream signaling activation. The specific EGFR downstream was not verified in this study, which will be done in further study.

This study reports that EGFR activation mediated PD-L1 expression in ESCC cells, which does not depend on EGFR-STAT3 signaling pathway, but may be associated with EGFR signaling network. As clinical studies of EGFR targeted therapy in esophageal cancer are still being performed and PD-L1-positive expression indicates poor prognosis in patients with esophageal cancer, ${ }^{45-47}$ further 
work emphasizing on the effect of crosstalk of EGFR signaling network on the regulation of PD-L1 expression in ESCC would provide potential and effective molecular pathways for tumor targeted therapy and immunotherapy.

\section{Acknowledgments}

This work was supported by the Science and Technology Project of Beijing (Z121107001012004); the Capital Foundation for Medical Research and Development (2007-2012); National Natural Science Foundation (81272512); and Chinese Hi-Tech R\&D Program (2012AA02A503).

\section{Ethical approval}

The Institutional Review Board of Cancer Hospital, Chinese Academy of Medical Science, approved the study protocol. All experiments were conducted in accordance with the Declaration of Helsinki.

\section{Disclosure}

The authors report no conflicts of interest in this work.

\section{References}

1. Pennathur A, Gibson MK, Jobe BA, Luketich JD. Oesophageal carcinoma. Lancet. 2013;381(9864):400-412.

2. Ayyappan S, Prabhakar D, Sharma N. Epidermal growth factor receptor (EGFR)-targeted therapies in esophagogastric cancer. Anticancer Res. 2013;33(10):4139-4155.

3. Zhang W, Zhu H, Liu X, et al. Epidermal growth factor receptor is a prognosis predictor in patients with esophageal squamous cell carcinoma. Ann Thorac Surg. 2014;98(2):513-519.

4. Jiang D, Li X, Wang H, et al. The prognostic value of EGFR overexpression and amplification in esophageal squamous cell carcinoma. $B M C$ Cancer. 2015;15:377.

5. Wang J, Yu JM, Jing SW, et al. Relationship between EGFR overexpression and clinicopathologic characteristics in squamous cell carcinoma of the esophagus: a meta-analysis. Asian Pac J Cancer Prev. 2014; 15(14):5889-5893.

6. Wang Q, Zhu H, Xiao Z, et al. Expression of epidermal growth factor receptor is an independent prognostic factor for esophageal squamous cell carcinoma. World J Surg Oncol. 2013;11:278.

7. Dayde D, Guerard M, Perron P, et al. Nuclear trafficking of EGFR by Vps34 represses Arf expression to promote lung tumor cell survival. Oncogene. 2016;35(30):3986-3994.

8. Luo N, Zhao LC, Shi QQ, Feng ZQ, Chen DL, Li J. Induction of apoptosis in human leukemic cell lines by diallyl disulfide via modulation of EGFR/ERK/PKM2 signaling pathways. Asian Pac J Cancer Prev. 2015;16(8):3509-3515.

9. Mizukami T, Togashi Y, Sogabe S, et al. EGFR and HER2 signals play a salvage role in MEK1-mutated gastric cancer after MEK inhibition. Int J Oncol. 2015;47(2):499-505.

10. Pivarcsi A, Muller A, Hippe A, et al. Tumor immune escape by the loss of homeostatic chemokine expression. Proc Natl Acad Sci U S A. 2007; 104(48):19055-19060.

11. Crosby T, Hurt CN, Falk S, et al. Chemoradiotherapy with or without cetuximab in patients with oesophageal cancer (SCOPE1): a multicentre, phase 2/3 randomised trial. Lancet Oncol. 2013;14(7):627-637.
12. Iyer R, Chhatrala R, Shefter T, et al. Erlotinib and radiation therapy for elderly patients with esophageal cancer-clinical and correlative results from a prospective multicenter phase 2 trial. Oncology. 2013;85(1): 53-58.

13. Mellman I, Coukos G, Dranoff G. Cancer immunotherapy comes of age. Nature. 2011;480(7378):480-489.

14. Chen J, Jiang CC, Jin L, Zhang XD. Regulation of PD-L1: a novel role of pro-survival signalling in cancer. Ann Oncol. 2016;27(3):409-416.

15. Hamanishi J, Mandai M, Matsumura N, Abiko K, Baba T, Konishi I. PD-1/PD-L1 blockade in cancer treatment: perspectives and issues. Int J Clin Oncol. 2016;21(3):462-473.

16. Butte MJ, Keir ME, Phamduy TB, Sharpe AH, Freeman GJ. Programmed death-1 ligand 1 interacts specifically with the B7-1 costimulatory molecule to inhibit T cell responses. Immunity. 2007;27(1):111-122.

17. McDermott DF, Atkins MB. PD-1 as a potential target in cancer therapy. Cancer Med. 2013;2(5):662-673.

18. Velcheti V, Schalper KA, Carvajal DE, et al. Programmed death ligand-1 expression in non-small cell lung cancer. Lab Invest. 2014;94(1): 107-116.

19. Schalper KA, Velcheti V, Carvajal D, et al. In situ tumor PD-L1 mRNA expression is associated with increased TILs and better outcome in breast carcinomas. Clin Cancer Res. 2014;20(10):2773-2782.

20. Taube JM, Anders RA, Young GD, et al. Colocalization of inflammatory response with B7-h1 expression in human melanocytic lesions supports an adaptive resistance mechanism of immune escape. Sci Transl Med. 2012;4(127):127ra137.

21. Chen R, Peng PC, Wen B, et al. Anti-programmed cell death (PD)-1 immunotherapy for malignant tumor: a systematic review and metaanalysis. Transl Oncol. 2016;9(1):32-40.

22. Borghaei H, Paz-Ares L, Horn L, et al. Nivolumab versus docetaxel in advanced nonsquamous non-small-cell lung cancer. $N$ Engl J Med. 2015;373(17):1627-1639.

23. Larkin J, Chiarion-Sileni V, Gonzalez R, et al. Combined nivolumab and ipilimumab or monotherapy in untreated melanoma. NEngl J Med. 2015;373(1):23-34.

24. Herbst RS, Baas P, Kim DW, et al. Pembrolizumab versus docetaxel for previously treated, PD-L1-positive, advanced non-small-cell lung cancer (KEYNOTE-010): a randomised controlled trial. Lancet. 2016; 387(10027):1540-1550.

25. Weber JS, D'Angelo SP, Minor D, et al. Nivolumab versus chemotherapy in patients with advanced melanoma who progressed after anti-CTLA-4 treatment (CheckMate 037): a randomised, controlled, open-label, phase 3 trial. Lancet Oncol. 2015;16(4):375-384.

26. Akbay EA, Koyama S, Carretero J, et al. Activation of the PD-1 pathway contributes to immune escape in EGFR-driven lung tumors. Cancer Discov. 2013;3(12):1355-1363.

27. Zhang Y, Wang L, Li Y, et al. Protein expression of programmed death 1 ligand 1 and ligand 2 independently predict poor prognosis in surgically resected lung adenocarcinoma. Onco Targets Ther. 2014;7: 567-573.

28. Concha-Benavente F, Srivastava RM, Trivedi S, et al. Identification of the cell-intrinsic and -extrinsic pathways downstream of EGFR and IFNgamma that induce PD-L1 expression in head and neck cancer. Cancer Res. 2016;76(5):1031-1043.

29. Chen MF, Chen PT, Chen WC, Lu MS, Lin PY, Lee KD. The role of $\mathrm{PD}-\mathrm{L} 1 \mathrm{in}$ the radiation response and prognosis for esophageal squamous cell carcinoma related to IL-6 and T-cell immunosuppression. Oncotarget. 2016;7(7):7913-7924.

30. Mishra R, Sefcik RS, Bishop TJ, et al. Growth factor dose tuning for bone progenitor cell proliferation and differentiation on resorbable poly(propylene fumarate) scaffolds. Tissue Eng Part C Methods. 2016; 22(9):904-913.

31. Zhang H, Nan W, Wang S, et al. Epidermal growth factor promotes proliferation and migration of follicular outer root sheath cells via wnt/ beta-catenin signaling. Cell Physiol Biochem. 2016;39(1):360-370. 
32. Azuma K, Ota K, Kawahara A, et al. Association of PD-L1 overexpression with activating EGFR mutations in surgically resected nonsmallcell lung cancer. Ann Oncol. 2014;25(10):1935-1940.

33. Tang Y, Fang W, Zhang Y, et al. The association between PD-L1 and EGFR status and the prognostic value of PD-L1 in advanced non-small cell lung cancer patients treated with EGFR-TKIs. Oncotarget. 2015; 6(16):14209-14219.

34. Topalian SL, Drake CG, Pardoll DM. Immune checkpoint blockade: a common denominator approach to cancer therapy. Cancer Cell. 2015; 27(4):450-461.

35. Parsa AT, Waldron JS, Panner A, et al. Loss of tumor suppressor PTEN function increases B7-H1 expression and immunoresistance in glioma. Nat Med. 2007;13(1):84-88.

36. Marzec M, Zhang Q, Goradia A, et al. Oncogenic kinase NPM/ALK induces through STAT3 expression of immunosuppressive protein CD274 (PD-L1, B7-H1). Proc Natl Acad Sci U S A. 2008;105(52): 20852-20857.

37. Abiko K, Matsumura N, Hamanishi J, et al. IFN-gamma from lymphocytes induces PD-L1 expression and promotes progression of ovarian cancer. Br J Cancer. 2015;112(9):1501-1509.

38. Mandai M, Hamanishi J, Abiko K, Matsumura N, Baba T, Konishi I. Dual faces of IFN-gamma in cancer progression: a role of PD-L1 induction in the determination of pro- and anti-tumor immunity. Clin Cancer Res. 2016;22(10):2329-2334.

39. Lienlaf M, Perez-Villarroel P, Knox T, et al. Essential role of HDAC6 in the regulation of PD-L1 in melanoma. Mol Oncol. 2016;10(5):735-750.
40. Sen M, Pollock NI, Black J, et al. JAK kinase inhibition abrogates STAT3 activation and head and neck squamous cell carcinoma tumor growth. Neoplasia. 2015;17(3):256-264.

41. Ota K, Azuma K, Kawahara A, et al. Induction of PD-L1 expression by the EML4-ALK oncoprotein and downstream signaling pathways in nonsmall cell lung cancer. Clin Cancer Res. 2015;21(17):4014-4021.

42. Lastwika KJ, Wilson W 3rd, Li QK, et al. Control of PD-L1 expression by oncogenic activation of the AKT-mTOR pathway in non-small cell lung cancer. Cancer Res. 2016;76(2):227-238.

43. Chen N, Fang W, Zhan J, et al. Upregulation of PD-L1 by EGFR activation mediates the immune escape in EGFR-driven NSCLC: implication for optional immune targeted therapy for NSCLC patients with EGFR mutation. J Thor Oncol. 2015;10(6):910-923.

44. Peng J, Hamanishi J, Matsumura N, et al. Chemotherapy induces programmed cell death-ligand 1 overexpression via the nuclear factorkappab to foster an immunosuppressive tumor microenvironment in ovarian cancer. Cancer Res. 2015;75(23):5034-5045.

45. Tanaka K, Miyata H, Sugimura K, et al. Negative influence of programmed death-1-ligands on the survival of esophageal cancer patients treated with chemotherapy. Cancer Sci. 2016;107(6):726-733.

46. Leng C, Li Y, Qin J, et al. Relationship between expression of PD-L1 and PD-L2 on esophageal squamous cell carcinoma and the antitumor effects of CD8+ T cells. Oncol Rep. 2016;35(2):699-708.

47. Chen L, Deng H, Lu M, et al. B7-H1 expression associates with tumor invasion and predicts patient's survival in human esophageal cancer. Int J Clin Exp Pathol. 2014;7(9):6015-6023.
OncoTargets and Therapy

\section{Publish your work in this journal}

OncoTargets and Therapy is an international, peer-reviewed, open access journal focusing on the pathological basis of all cancers, potential targets for therapy and treatment protocols employed to improve the management of cancer patients. The journal also focuses on the impact of management programs and new therapeutic agents and protocols on

\section{Dovepress}

patient perspectives such as quality of life, adherence and satisfaction. The manuscript management system is completely online and includes a very quick and fair peer-review system, which is all easy to use. Visit http://www.dovepress.com/testimonials.php to read real quotes from published authors. 